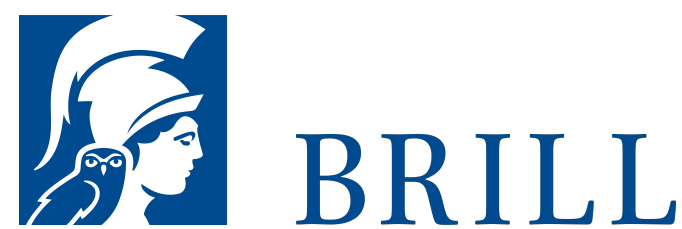

\title{
Materie - Kausalität - Erleben
}

Analytische Metaphysik des Panpsychismus

Author: Matthias Rugel

Die Geist-Gehirn-Debatte in der analytischen Philosophie konzentriert sich am Beginn des 21. Jahrhunderts auf die Einordnung des phänomenalen Erlebens. Der Physikalist versteht das Erleben funktional, der Dualist als etwas, das außerhalb des Bereichs der Physik steht. Der Panpsychist besetzt die Mitte zwischen diesen Extrempositionen. Er setzt Erleben weder mit Gehirnfunktionen gleich, noch setzt er es ihnen als etwas Eigenständiges gegenüber. Erleben kommt bereits der untersten Ebene der Natur zu. Nur weil die kleinsten Bestandteile der Materie erleben, kann es menschliches Erleben geben. Sowohl der Urknall als auch die erste Zelle mit dem Erbgut eines werdenden Menschen hat eine subjektive Erlebniskomponente. Das Erleben ist die intrinsische Natur aller natürlichen materiellen Einheiten. Autoren wie Thomas Nagel, Karl Popper oder David Chalmers haben in Richtung eines Panpsychismus gedacht, aber die Position nicht ausgearbeitet. Um sie als Alternative zu den herrschenden Paradigmen einzuführen, ist eine Neubestimmung grundlegender Begriffe wie Materie, Kausalität oder Individualität erforderlich. Erst im letzten Jahrzehnt haben sich einige Autoren dieser Aufgabe angenommen, vor allem Gregg Rosenberg und Galen Strawson. In Auseinandersetzung mit ihren Thesen und mit Blick auf die zeitgenössischen Naturwissenschaften entwickelt dieses Buch eine eigenständige panpsychistische Theorie.

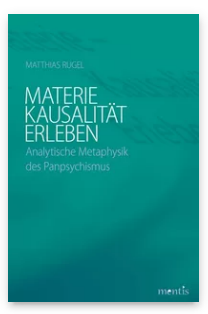

Pages: 375

Seiten

Language:

German

Subjects:

General,

Philosophy

Publisher: Brill | mentis

E-Book (PDF)

Released online:

o1 Jan 2013

ISBN: $978-3^{-}$

95743-954-3

List price

Paperback

Publication date:

o1 Jan 2013

ISBN: 978-3-

89785-802-2

List price 
For more information see brill.com

Order information: Order online at brill.com +44330 333 0049 | customerservices@brill.com Submission information: brill.com/authors

Titles published by Brill | Fink, Brill | mentis or Brill | Schöningh: +49(o)715413279216| brill@brocom.de 